\title{
Maxillary implant-supported overdenture with magnetic attachment using healing abutment: A case report
}

\author{
Jae-Hoon Kim, Ha-Rim Lee, Eun-Sun Jang, and Gyeong-Je Lee*
}

Department of Prosthodontics, School of Dentistry, Chosun University, Gwangju, Republic of Korea

\begin{abstract}
Herein, we report the use of a maxillary implant-supported overdenture with magnetic attachment using healing abutments. A 57-yearold male presented with multiple tooth loss in the maxilla along with chronic periodontitis. He had a history of diabetes mellitus and a smoking habit. Rehabilitation was initiated using fixed prostheses. However, the treatment plan was altered to implant-supported overdenture owing to poor bone status and multiple failures of the implants. The magnetic attachment system was selected for the implant-supported overdenture without the use of a locator or bar type attachment. The implants used in the patient were not provided with a magnetic attachment for the overdenture; therefore, healing abutments were modified so that the magnetic attachments could be capped above them. The final prosthesis was satisfactory both functionally and esthetically.
\end{abstract}

Key Words: Implant failure, Implant overdenture, Magnet, Magnetic attachment using healing abutment

(c) This is an open-access article distributed under the terms of the Creative Commons Attribution Non-Commercial License (http://creativecommons.org/licenses/by-nc/4.0) which permits unrestricted noncommercial use, distribution, and reproduction in any medium, provided the original work is properly cited.

\section{서 론}

오늘날 치과 임플란트는 단일 또는 다수 치아가 결손된 무치 악 부위의 보철 치료에 널리 사용되고 있으며, 치아 임플란트의 장기적 성공은 여러 문헌에 의해 뒷받침 되고 있다[1,2].

환자에 따른 임플란트 성공 여부[3]에는 다양한 요인들이 작 용하게 되는데, 특히 당뇨와 흡연, 치주염 등의 요인이 임플란트 실패를 야기한다고 보고되고 있다[4-8]. 점차 임플란트를 이용 한 치료가 늘어남에 따라 임플란트의 실패뿐만 아니라 임플란 트와 관련하여 발생할 수 있는 다양한 합병증 및 예측하지 못한 상황에 대하여 유연하게 대응할 필요가 있다[9,10].

본 증례의 환자는 상악 전악 고정성 임플란트 보철 수복을 계 획하여 임플란트를 식립하였으나 다수 임플란트가 골유착에 실 패하였다. 잔존 임플란트는 호환되는 자성 어태치먼트가 없어
치유지대주를 이용하여 제작한 자성 어태치먼트를 부착한 임플 란트 지지 가철성 피개의치로 치료하여 생역학적으로 비교적 안정적이고 기능적, 심미적으로 만족스러운 결과를 얻었기에 이를 보고하고자 한다.

\section{증례보고}

본 증례는 전반적인 치주염으로 인한 다수 치아 상실 상태로 내원하였으며 당뇨, 흡연의 전신병력이 있는 57세 남자 환자이 다.

초진 내원 시 상악의 잔존치아(\#13, 23)는 치주염으로 심한 동요를 보이는 상태로 발거하였다(Fig. 1A). 상악 완전 무치악 에 대해 다수 임플란트 식립을 통한 고정성 보철 수복을 계획하 여 총 8개(\#11, 15, 16, 17, 22, 25, 26, 27)의 임플란트가 식립

Received September 9, 2019; Revised October 16, 2019; Accepted October 16, 2019

*Corresponding author: Gyeong-Je Lee, Department of Prosthodontics, School of Dentistry, Chosun University, 303 Pilmun-daero, Dong-gu, Gwangju 61452, Republic of Korea.

Tel: +82-62-220-3820, Fax: +82-62-224-6269, E-mail: lkj1998@Chosun.ac.kr

Copyright @ 2019, Oral Biology Research Institute 

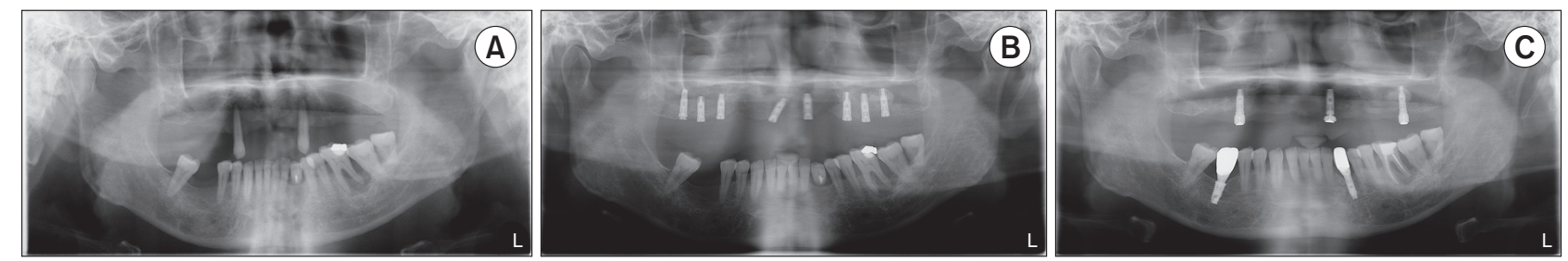

Fig. 1. Panoramic view. (A) First visit. (B) Six months after implant placement. (C) After final maxillary implant overdenture delivery.

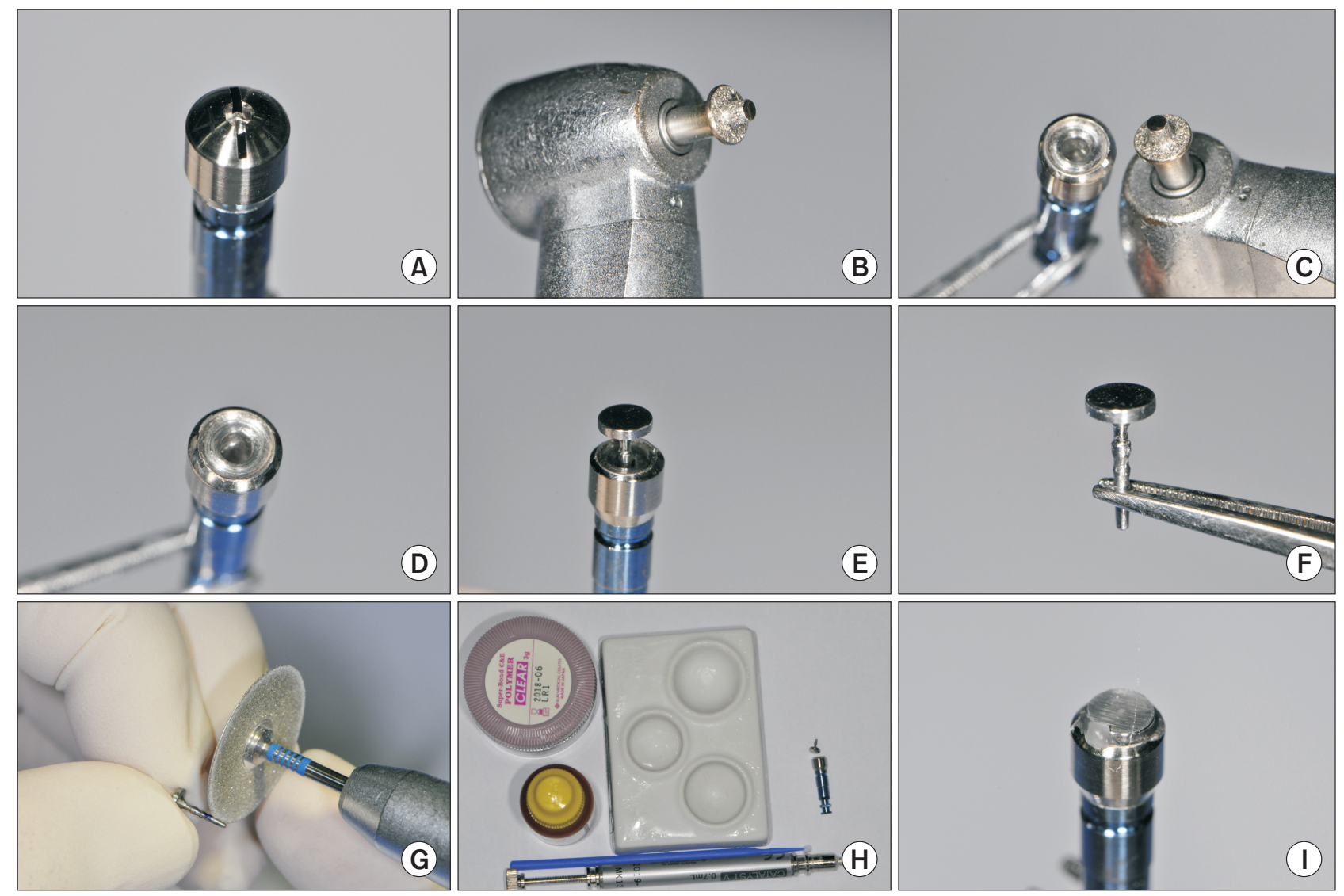

Fig. 2. Processing and assembly of healing abutment and magnetic attachment (keeper). (A) Healing abutment of 3i. (B) Bur prepared for processing. (C, D) Bed formation on healing abutment. (E-G) Cutting of Magfit SX keeper post area. (H, I) Superbond cementation.

되었다(Fig. 1B). 식립된 8개 임플란트 가운데 식립 후 20개월이 경과하여 시행된 2차 수술 이후까지 3개의 임플란트(\#11, 17, 25)가 골유착에 실패하였다. 상악의 잔존 임플란트를 활용하여 추가적인 골이식 및 임플란트 식립을 시행하지 않고 상악의 잔 존 임플란트를 활용한 가철성 임플란트 피개의치를 제작하는 방향으로 치료계획을 수정하였다. 치료계획 수정 후 추가적인 임플란트의 골유착 실패 $(\# 16,26)$ 가 발생하여 상악에서 3개의 임플란트(\#15, 22, 27)만이 남았다(Fig. 1C).

환자는 반복적인 임플란트 실패를 보이는 골 상태와 함께 대 합치열 또한 고르게 배열되지 않은 상태를 보였다. 편악 가철성
보철물로써 소수 잔존 임플란트에 가해지는 역학적 요소를 고 려한 어태치먼트의 선택이 중요하다.

임플란트 피개의치를 위한 여러 어태치먼트 종류 가운데 자 성 어태치먼트는 ERA, Locator, O-ring 또는 바 타입의 다른 연 결장치에 비하여 유지력이 부족한 것으로 알려져 있으나, 유해 한 측방력을 감소 시키는 면에서 특히 유리하다. 이에 본 증례에 서는 Locator 또는 바형 장치가 아닌 자석형 장치를 사용한 피 개의치를 위한 어태치먼트로 선택하였다[11,12].

한편, 식립된 임플란트(3i Certain; Biomet $3 \mathrm{i}$ Co., West Palm Beach Gardens, FL, USA)는 제조사에서 자성 어태치먼 
트(keeper)를 제공하지 않고, 독특한 내부구조를 가져 다른 임 플란트 제품과의 호환이 어렵다. 이러한 문제점을 해결하기 위 하여 동일 회사의 치유지대주와 자연치아용 자성 어태치먼트인 Magfit SX (Aichi Steel Corp., Tokai, Japan)를 이용하여 피개 의치용 자성 어태치먼트를 제작하여 활용하였다.

임플란트 피개의치 제작을 위하여 통상적인 상악 총의치 제 작 과정이 진행되었다. 알지네이트와 무치악 기성트레이를 이 용하여 예비인상을 채득하여 진단모형을 제작하였다. 진단모형 상에서 치조제에 맞추어 개인트레이를 제작하였다.

피개의치에 사용될 어태치먼트를 Fig. 2와 같은 과정을 거 쳐 제작하였다. 자성 어태치먼트가 합착된 치유지대주를 구강 내 임플란트에 체결한 상태(Fig. 2A-C)에서 어태치먼트 부속 품(plastic dummy)을 이용하여 임플란트 피개의치 내면에 부 착될 자석 구조체(magnetic assembly) 부분의 공간을 부여한 후 최종 인상채득 과정을 진행하였다. 인상채득을 위하여 개인 트레이와 모델링 콤파운드(Pericom pound; GC Co., Tokyo, Japan)를 이용하여 변연형성하였으며, 폴리설파이드 인상재 (Permlastic; Kerr Corp., Orange, CA, USA)를 이용하여 기능
인상 채득하였다. 초경석고(Fujirock EP; GC Co., Leuven, Belgium)를 이용하여 상악 주모형을 제작하였으며, 해부학적 지표 및 대합치 관계를 고려하여 기록상 및 교합제를 제작하였다.

제작한 교합제를 구강 내에 시적하여 통상적인 방법에 따라 수직고경을 결정하였으며 알루왁스(Aluwax; Dental Products Co., Allendale, MI, USA)를 이용하여 중심위 관계기록을 채득 하였다. 교합기 부착 후 인공치를 배열하였으며 군기능교합을 형성하여 납의치를 제작하였다.

심미성과 함께 지지, 유지, 안정의 3요소를 갖춘 상악 총의치 제작을 위해서는 대합치와의 긴밀한 교합관계 설정이 중요하 며, 편측 상악의치에서 대합치와의 긴밀한 교합관계는 더욱 중 요하다[13-17]. 대합치의 고르지 못한 배열로 인하여 양측성 균 형교합의 교합양식을 형성하기에는 어려움이 있으며, 식립된 임플란트에서 유지와 안정을 보충하는 임플란트 피개의치임을 고려하여 낮은 교두 경사의 군기능 교합양식으로 설정하기로 계획하였다.

제작한 납의치를 구내에 시적하여 구순 지지와 정중선 위치 등을 확인하였고(Fig. 3D-I), 특이사항 없이 의치의 중합을 시행
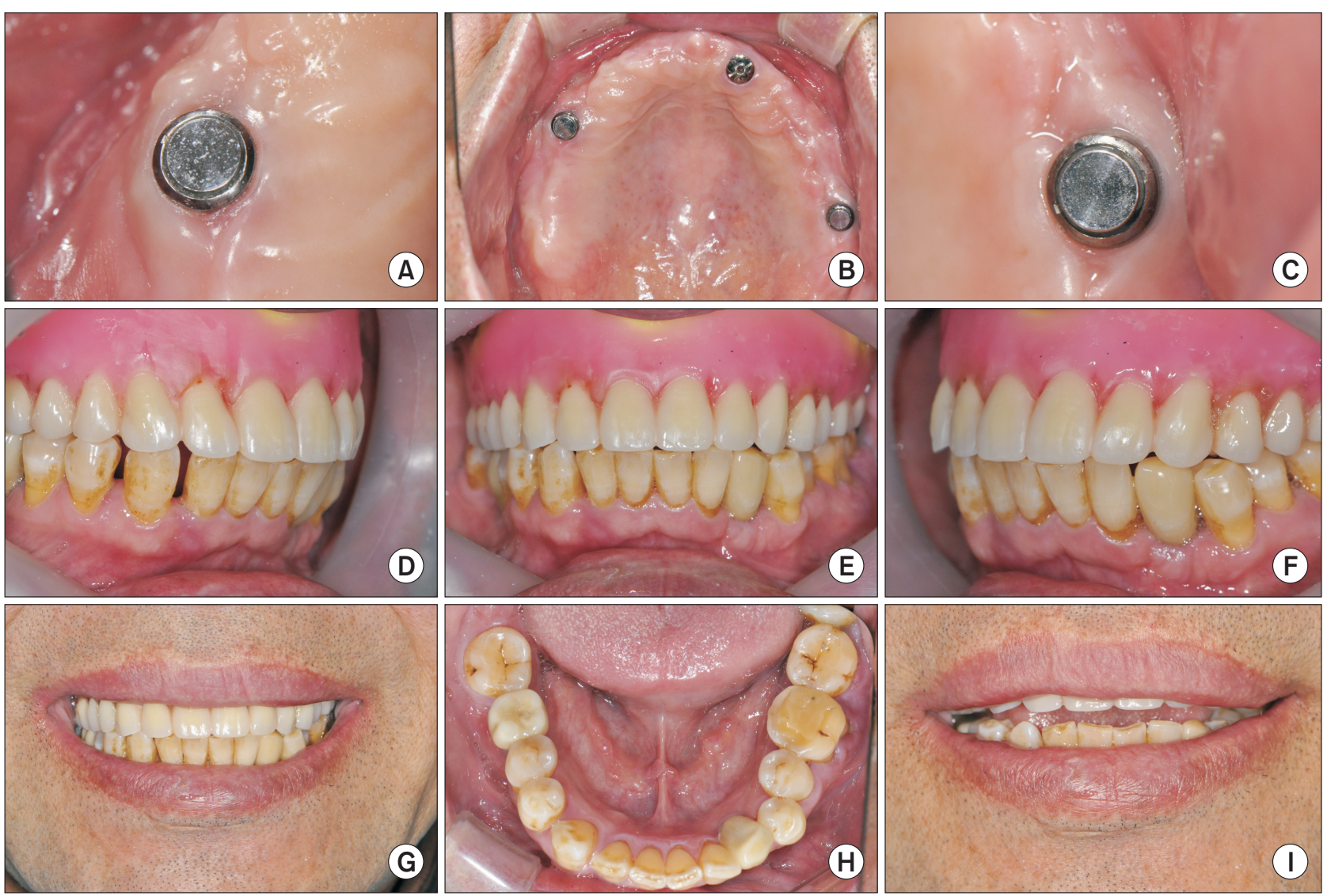

Fig. 3. (A-C) Magnetic attachment placed over \#15, 22, 27 healing abutment. (D-F, H) Wax denture try-in. (G, I) Facial with wax denture in centric relation and in rest position. 
하였다.

최종의치의 내면적합 및 릴리프 공간을 확인한 후 자석 구 조체를 위치시키고, 자가중합레진(Duralay; Reliance Dental Manufacturing Co., Worth, IL, USA)을 이용하여 의치 내면에 자석 구조체를 부착하였다. 진료실 재부착을 시행하여 교합조 정 시행하였다(Fig. 4). 최종적으로 구강 내에서 임플란트 피개의 치의 양호한 내면 적합과 교합형성 결과를 확인하였다(Fig. 5).

\section{고 찰}

무치악 환자의 임플란트 치료에 대한 임상증례는 다양하게 보고되고 있으나, 임플란트가 수술적으로 또는 보철적으로 실 패한 경우에 재진단 과정을 거쳐 기존 임플란트를 활용한 임상 증례는 많지 않다 $[9,10]$.

Goodacre 등[18]은 상악 임플란트 피개의치가 상악 고정성 임플란트 보철물보다 더 빈번한 임플란트 고정체 상실과 합병 증이 발견된다고 보고하였다.

한편, 임플란트 피개의치는 임플란트 고정성 보철물과 비교 하여 다음의 장점을 가진다고 알려져 있다. (1) 적은 수의 임플 란트를 사용하여 제작할 수 있으며 골이식의 필요성이 감소한 다. (2) 수술 및 기공 과정이 보다 단순하고 용이하다. (3) 보다 적은 비용으로 제작할 수 있다[19-21].

자성 어태치먼트는 바 타입 어태치먼트 또는 볼 타입 어태치
먼트와 비교하여 유지력이 떨어진다는 단점을 가지는 반면 충 분한 유지력이 확보되는 경우 다음의 장점을 얻을 수 있다. (1) 낮은 수직 높이로 악간공간이 부족한 경우에도 사용할 수 있으 며 보다 나은 심미성을 얻을 수 있다. (2) 기공 과정이 간단한 편 이며, 캐스팅 과정을 필요로 하지 않는다. (3) 바 또는 클립 파절 등의 문제가 발생하지 않는다. (4) 볼 타입에서 필요한 O-ring 또는 Locator의 교체가 필요하지 않다. (5) 수평적으로 큰 힘이 작용하지 않기 때문에 임플란트에 가해지는 유해한 측방력이 작다. (6) 삽입철거로에 대한 제한이 적으며 이에 따라 식편압입 이 발생할 가능성도 적다[11,12].

자성 어태치먼트의 여러 장점들 가운데 임플란트에 가해지는 유해한 측방력이 작다는 점은 임플란트의 장기적인 좋은 예후 를 위한 우수한 조건으로 평가된다[11].

본 증례에서는 3 개의 임플란트와 자성 어태치먼트를 이용한 피개의치를 제작하여 1 년여 경과 관찰 기간에서는 의치상의 파 절이나 유지력의 상실, 기존 임플란트의 실패 등의 다른 부작용 이 관찰되지 않았으나 앞으로도 주기적인 경과 관찰로 지속적 인 평가가 필요하다.

임플란트를 이용한 치료는 치아 상실에 대하여 양호한 치료 방법으로 이용되고 있다. 임플란트와 관련하여 발생할 수 있는 다양한 합병증 및 예측하지 못한 상황에 대해 유연한 대응이 필 요하다. 본 증례는 이러한 어려운 상황에 대한 대처로 추가적인 임플란트 식립 없이 기능적, 심미적으로 만족스러운 결과를 얻
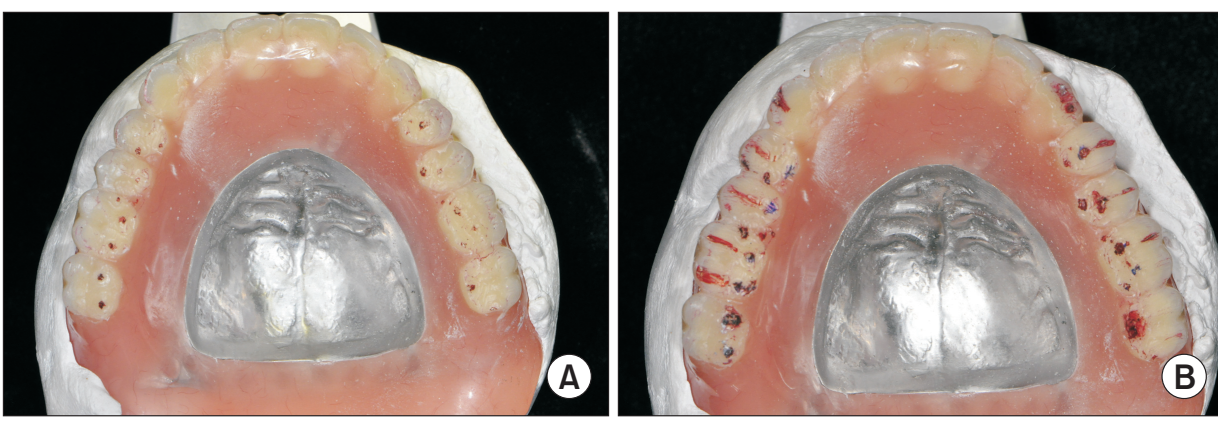

Fig. 4. Occlusal adjustment. (A) Centric relation. (B) Eccentric movement (group function).
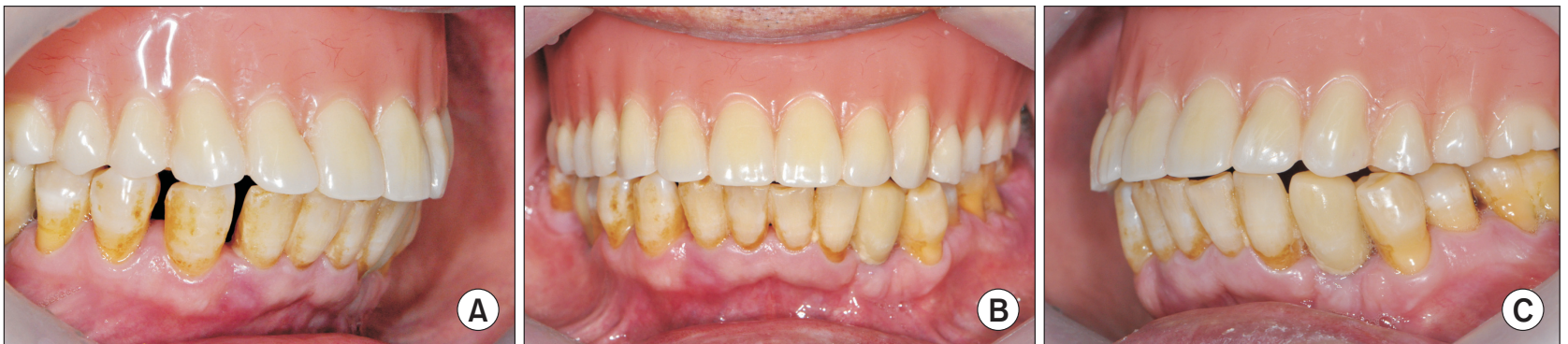

Fig. 5. Intraoral view on definitive prosthesis delivery. (A) Right lateral view. (B) Frontal view. (C) Left lateral view. 
었기에 이를 보고하는 바이다.

\section{CONFLICTS OF INTEREST}

The authors declare that they have no competing interests.

\section{ORCID}

\author{
Jae-Hoon Kim \\ https://orcid.org/0000-0002-2807-6707 \\ Ha-Rim Lee \\ https://orcid.org/0000-0002-3501-3472 \\ Eun-Sun Jang \\ https://orcid.org/0000-0002-2596-2551 \\ Gyeong-Je Lee \\ https://orcid.org/0000-0002-3545-2280
}

\section{REFERENCES}

1. Adell R, Lekholm U, Rockler B, Brånemark PI. A 15-year study of osseointegrated implants in the treatment of the edentulous jaw. Int J Oral Surg 1981;10:387-416. doi: 10.1016/s0300-9785(81)80077-4.

2. Adell R, Eriksson B, Lekholm U, Brånemark PI, Jemt T. Long-term follow-up study of osseointegrated implants in the treatment of totally edentulous jaws. Int J Oral Maxillofac Implants 1990;5:347-359.

3. Smith DE, Zarb GA. Criteria for success of osseointegrated endosseous implants. J Prosthet Dent 1989;62:567-572. doi: 10.1016/0022-3913(89)90081-4.

4. Javed F, Romanos GE. Impact of diabetes mellitus and glycemic control on the osseointegration of dental implants: a systematic literature review. J Periodontol 2009;80:17191730. doi: 10.1902/jop.2009.090283.

5. Naujokat H, Kunzendorf B, Wiltfang J. Dental implants and diabetes mellitus-a systematic review. Int J Implant Dent 2016;2:5. doi: 10.1186/s40729-016-0038-2.

6. Retzepi M, Donos N. The effect of diabetes mellitus on osseous healing. Clin Oral Implants Res 2010;21:673-681. doi: 10.1111/j.1600-0501.2010.01923.x.

7. Lindquist LW, Carlsson GE, Jemt T. Association between marginal bone loss around osseointegrated mandibular implants and smoking habits: a 10-year follow-up study. J Dent Res 1997;76:1667-1674. doi: 10.1177/00220345970760100801.

8. Strietzel FP, Reichart PA, Kale A, Kulkarni M, Wegner B,
Küchler I. Smoking interferes with the prognosis of dental implant treatment: a systematic review and meta-analysis. J Clin Periodontol 2007;34:523-544. doi: 10.1111/j.1600051X.2007.01083.x.

9. Kim JS, Jeon YC, Jeong CM, Yun MJ, Huh JB. A conversion to implant overdenture in failed fixedimplant prosthesis of edentulous maxilla: a case report. J Korean Acad Prosthodont 2016;54:393-400. doi: 10.4047/jkap.2016.54.4.393.

10. Yang SW, Kim JE, Kim JH. Eight-year follow-up of two different removable prostheses using six implants in maxillary edentulous patients. J Korean Acad Prosthodont 2017;55:300-304. doi: 10.4047/jkap.2017.55.3.300.

11. Fujimoto T, Niimi A, Murakami I, Ueda M. Use of new magnetic attachments for implant-supported overdentures. J Oral Implantol 1998;24:147-151. doi: 10.1563/1548-1336(1998)024〈0147:UONMAF〉2.3.CO;2.

12. Chung KH, Chung CY, Cagna DR, Cronin RJ Jr. Retention characteristics of attachment systems for implant overdentures. J Prosthodont 2004;13:221-226. doi: 10.1111/ j.1532-849X.2004.04042.x.

13. Ellinger CW, Rayson JH, Henderson D. Single complete dentures. J Prosthet Dent 1971;26:4-10. doi: 10.1016/0022-3913(71)90023-0.

14. Bruce RW. Complete dentures opposing natural teeth. J Prosthet Dent 1971;26:448-455. doi: 10.1016/00223913(71)90002-3.

15. Rudd KD, Morrow RM. Occlusion and the single denture. J Prosthet Dent 1973;30:4-10. doi: 10.1016/00223913(73)90070-x.

16. Koper A. The maxillary complete denture opposing natural teeth: problems and some solutions. J Prosthet Dent 1987;57:704-707. doi: 10.1016/0022-3913(87)90367-2.

17. Tan HK. A preparation guide for modifying the mandibular teeth before making a maxillary single complete denture. J Prosthet Dent 1997;77:321-322. doi: 10.1016/s00223913(97)70190-2.

18. Goodacre CJ, Bernal G, Rungcharassaeng K, Kan JY. Clinical complications with implants and implant prostheses. J Prosthet Dent 2003;90:121-132. doi: 10.1016/S00223913(03)00212-9.

19. DeBoer J. Edentulous implants: overdenture versus fixed. J Prosthet Dent 1993;69:386-390. doi: 10.1016/00223913(93)90186-r.

20. Zitzmann NU, Marinello CP. Treatment plan for restoring the edentulous maxilla with implant-supported restorations: removable overdenture versus fixed partial denture design. J Prosthet Dent 1999;82:188-196. doi: 10.1016/ s0022-3913(99)70155-1.

21. Andreiotelli M, Att W, Strub JR. Prosthodontic complications with implant overdentures: a systematic literature review. Int J Prosthodont 2010;23:195-203. 